Published in final edited form as:

Clin Gastroenterol Hepatol. 2015 November ; 13(12): 2048-2061. doi:10.1016/j.cgh.2015.06.039.

\title{
Covert and Overt Hepatic Encephalopathy: Diagnosis and Management
}

Kavish R. Patidar, D.O. ${ }^{1}$ and Jasmohan S. Bajaj, M.D. ${ }^{1}$

${ }^{1}$ Division of Gastroenterology, Hepatology and Nutrition, Virginia Commonwealth University and McGuire VA Medical Center, Richmond, Virginia, USA

\section{Abstract}

Hepatic encephalopathy (HE) is part of a spectrum of neurocognitive changes in cirrhosis. HE is divided into two broad categories based on severity, covert (CHE) and overt (CHE). CHE has a significant impact on a patient's quality of life, driving performances, and has recently been associated with increased hospitalizations and death. Likewise, OHE is associated with increased rates of hospitalizations and mortality, and poor quality of life. Given its significant burden on patients, care takers, and the health care system, it's imperative for early diagnosis and management. In addition, a focus should also be directed on patient and family member education on the disease progression and adherence to medications. Treatment strategies include the use of non-absorbable disaccharides, antibiotics (i.e. rifaximin), and potentially probiotics. Other therapies currently under further investigation include: L-ornithine-L-aspartate, ornithine phenylacetate, glycerol phenylbutyrate, molecular adsorbent recirculating system, and albumin infusion.

\section{Keywords}

Cirrhosis; Covert Hepatic Encephalopathy; Overt Hepatic Encephalopathy; Hepatic

Encephalopathy; Ammonia; lactulose; Rifaximin

\section{INTRODUCTION}

Hepatic encephalopathy (HE) is a prevalent complication of portal hypertension and cirrhosis that is seen in $50-70 \%$ of patients ${ }^{1}$. It manifests as a spectrum of neuropsychiatric abnormalities that is usually found in patients with portosystemic shunting and cirrhosis ${ }^{2}$.

According to the new AASLD/EASL guidelines, HE is classified into 4 axes which consist of the type of the underlying problem, disease severity, time course, and onset (Table 1) $)^{3}$. These axes are critical to evaluate HE episodes in context of the underlying clinical

Corresponding Author: Jasmohan S Bajaj, MD, MSc, FACG, AGAF, Division of Gastroenterology, Hepatology and Nutrition, Virginia Commonwealth University and McGuire VA Medical Center, 1201 Broad Rock Boulevard, Richmond, Virginia, USA, Telephone: (804) 675-5021, Fax: (804) 675-5816, jsbajaj@ vcu.edu.

Publisher's Disclaimer: This is a PDF file of an unedited manuscript that has been accepted for publication. As a service to our customers we are providing this early version of the manuscript. The manuscript will undergo copyediting, typesetting, and review of the resulting proof before it is published in its final citable form. Please note that during the production process errors may be discovered which could affect the content, and all legal disclaimers that apply to the journal pertain.

Disclosures: none for KP, JSB has served as a consultant for Salix, Merz and Norgine. 
condition. For example, describing the axes in a cirrhotic woman with her second episode of HE due to a urinary tract infection (UTI) who is disoriented to time with asterixis would be "Type C, Grade 2, Recurrent and Precipitated Overt HE". Defining each HE episode in these four axes would encourage clinicians to investigate potential root causes i.e. UTI in patients to prevent recurrence and potentially improve management.

According to severity, HE can be divided into two broad categories: covert HE (CHE) and overt $\mathrm{HE}(\mathrm{OHE})^{4}$, which are both part of the spectrum of neurocognitive impairment in cirrhosis (SONIC) ${ }^{5}$. The prevalence of CHE has been reported in 30-85\% of cirrhotics when tested $^{6,7}$, whereas OHE is estimated to occur in up to $30-50 \%$ in patients with cirrhosis, with an annual risk for development of $20 \%{ }^{8}$. This incidence for development is also associated with high rates of hospitalizations, which continues to rise ${ }^{9}$, along with increased healthcare $\operatorname{cost}^{10}$. In addition, there is substantial data to reflect its negative impact on patients' health related quality of life (HRQOL) ${ }^{11}$, and on survival independent from the severity of cirrhosis ${ }^{1,12,13}$.

CHE is regarded as the pre-clinical stages of OHE (which consists of minimal HE, MHE, and West Haven grade $1 \mathrm{HE}^{14}$ ). The entity CHE was created by combining MHE and grade I HE because of the poor reliability of the grade I stage. Therefore under the new classification, OHE starts with grade 2 or with evidence of asterixis and disorientation. CHE has several prognostic implications ${ }^{5}$. It is associated with increased progression to $\mathrm{OHE}^{15}$, poor HRQOL ${ }^{16}$, and high risk for traffic violations and accidents ${ }^{17}$. CHE is also an independent predictor for death and hospitalizations ${ }^{18}$.

The burden of CHE and OHE is vast given their effects on the patient, family and society. Considering that these syndromes affect HRQOL, driving, ability to work, and health care costs, it important for a clinician to recognize and treat CHE and OHE in an effort to improve these conditions. Thus, this review will cover the pathophysiology, diagnosis, and management of CHE and OHE.

\section{PATHOPHYSIOLOGY}

The pathophysiology of HE (overt and covert) is complex with multiple components, which act alone or in combination (Figure 1), with an end product of functional neuronal impairment. These components include ammonia, inflammatory cytokines, benzodiazepinelike compounds, and manganese deposition ${ }^{19}$.

\section{Ammonia}

There is robust evidence that ammonia plays an important role in the pathogenesis of HE. Ammonia is generated from nitrogenous products in the diet, bacterial metabolism of urea and proteins in the gut, and from deamination of glutamine in the small intestine via glutaminase ${ }^{20}$. Normally, ammonia is converted to urea in the liver and then subsequently cleared by kidneys. A small amount is also cleared by skeletal muscle via glutamate. However, as a result of liver dysfunction, portosystemic collaterals and sarcopenia in cirrhosis, ammonia cannot be cleared adequately and subsequently ammonia concentration rises in the blood and crosses the blood-brain barrier $(\mathrm{BBB})^{21}$ leading to brain edema ${ }^{22}$. 
Continued exposure of ammonia in the brain also leads to other physiological disturbances. For example, ammonia may bind to the GABA receptor complex on astrocytes, which may trigger synthesis of neurosteroids, which are GABA agonists ${ }^{23}$. Other neurotransmitters, such as serotonin, acetylcholine, glutamate, and monamines, have also been suggested to contribute in the pathogenesis of HE.

\section{Inflammation and Microbiota}

Inflammation is an important patho-physiological component of HE. The pro-inflammatory milieu in cirrhosis is associated with liver inflammation and alterations of intestinal microbiota, which is worsened by infections, gastrointestinal bleeding and obesity. This proinflammatory milieu and gut dysbiosis ${ }^{24}$ is associated with the release of pro-inflammatory cytokines, such as interleukin 1 (IL-1), IL-6, and tumor necrosis factor (TNF). These cytokines work in conjunction with ammonia to contribute to the development of cerebral edema in $\mathrm{HE}^{25}$.

\section{DIAGNOSIS OF HEPATIC ENCEPHALOPATHY}

\section{CHE: DIAGNOSIS}

CHE is a challenging diagnosis to make given that there is no disorientation or asterixis on examination. However, patients with grade 1 West Haven Criteria (WHC) HE, who are currently included in the realm of CHE, may have cognitive complaints brought by themselves or by their companions. Patients with CHE have abnormalities on psychometric testing, particular in areas of attention, executive functions, visuo-spatial coordination, and psychomotor speed/reactions times ${ }^{26}$. Thus, testing strategies focus on finding abnormalities using paper-pencil, computerized or neurophysiologic tests. The choice of which tests or battery to select should be driven by the availability of local normative data, cost, and expertise (Table 2). The strategies for diagnosis are screening with high-sensitivity tests that can then be used to determine whether patients are likely to have CHE or to test all relevant patient populations using recommended tests. Of the three categories of tests, 2 need to be abnormal in multi-center studies while 1 testing strategy may be enough for single-center studies in recent guidelines ${ }^{3,4}$.

Paper-pencil Testing-A paper and pencil test battery called Psychometric Hepatic Encephalopathy Score (PHES) is often regarded as the gold standard ${ }^{2}$. PHES is highly sensitive and specific (96\% and 100\% respectively) for determining CHE (total cut-off score $<-4)$, with a score $<-6$ conferring a poor prognosis ${ }^{17}$. In places where there are no PHES normative reference values, it is recommended that at least 2 of the following neuropsychological tests be used: NCT-A, NCT-B, block design, and digit symbol test.

Repeatable Battery for the Assessment of Neuropsychological Status (RBANS) is a 20-25 minutes paper-and-pencil battery to diagnose $\mathrm{CHE}^{27}$. It includes copyrighted sets of tests that assess cortical and subcortical domains. Lately however, it has not been used in this field due to two domains (language and delayed memory) being relatively preserved in CHE with relatively poor performance in $\mathrm{HE}^{28}$. 
Computerized tests-Inhibitory Control Test (ICT) is a computerized test that evaluates inhibition, attention span, vigilance, and working memory ${ }^{29}$. Here, a patient responds to target letters (such as $\mathrm{X}$ and $\mathrm{Y}$ ) and not to lures (non $\mathrm{X}$ and $\mathrm{Y}$ targets). CHE is diagnosed when patients have longer reaction times, lower rate of target responses, and higher rate of lure responses with a sensitivity and specificity of $87 \%$ and $77 \%$ respectively ${ }^{32}$. The ICT is easy to administer, free, and validated, however it requires highly functional patients.

The Cognitive Drug Research (CDR) battery is another tool used to diagnose $\mathrm{CHE}^{30}$. Impairment in all domains characterizes a patient with CHE comparable to the PHES. CDR has good validity, easy to use, and inexpensive. However it has not been validated for the US population.

Lastly, the EncephalApp Stroop smartphone $\mathrm{App}^{31}$ is a short and valid tool used to screen for CHE. The application tests psychomotor speed and cognitive alertness via measuring the time to correctly identify a series of symbols with different colors ("off-time") and printed words with different colors ("on-time"). A cut off of >190 seconds identified CHE with excellent accuracy ${ }^{32}$. The application is free, easy to use, accessible, and may be ideal for centers who do not have access to formal testing, or for clinicians who are interested in rapid screening to separate out patients who would otherwise test normal on formal testing.

Neurophysiological Testing-Electroencephalography (EEG) is an electrophysiological test that can be used to access neuropsychiatric impairments in cirrhosis ${ }^{33}$. The sensitivity for diagnosing HE ranges from $43 \%$ to $100 \%^{34}$. EEG is associated with both inter and intra observer variability. In addition, it is resource intensive by requiring a technician and a neurologist, costly, and thus may not be ideal to diagnose CHE.

The clicker flicker frequency (CFF) test measures cortical function, and correlates well with those of psychometric tests ${ }^{35}$. Here patients are shown light pulses at an initial frequency of $60 \mathrm{~Hz}$ and gradually reduced by $0.1 \mathrm{~Hz}$ per second. Patients are asked to identify the time of which of the light begins to flicker. A CFF below $39 \mathrm{~Hz}$ accurately diagnoses CHE by 73$83 \%$ and correlates well with PHES $^{36}$. CFF can be affected by medications, age, and equipment used ${ }^{5}$. However even with its limitations, the CFF is a simple, valid, and effective tool that can be used to diagnose CHE.

Evoked potentials, visual, auditory, and somatosensory, have also been used to diagnose $\mathrm{CHE}^{8}$. These tests, however, are highly variable with inconsistent results.

Pragmatic approach to CHE screening and diagnosis: While most of the tests mentioned above are validated, they are often difficult to perform in clinical practice. So pragmatic cognitive solutions that can potentially be administered and interpreted by medical assistants, nurses or allied health practitioners are a potential "vital sign" could be relevant. It is also important to note that cognitive testing could also be performed outside the clinic on a separate appointment, such as prior to ultrasound etc. to reduce the burden on the clinic staff.

The simplest screening/diagnostic approaches are the use of HRQOL questionnaires such as 4 questions of the Sickness Impact Profile ${ }^{37}$ and the use of EncephalApp Stroop ${ }^{32}$. If all 4 
specific questions in the SIP ("I am eating much less than usual", "I am not doing any of my usual physican recreation or activities", "I do not maintain balance" and "I act irritable or impatient with myself") are positive, there is an $80 \%$ likelihood of CHE. Similarly as mentioned above, $>190$ seconds value on EncephalApp Stroop also has $>80 \%$ sensitivity for CHE diagnosis.

These tests have good negative prediction value, therefore patients performing normally on them can potentially be re-tested in 6 months while only those who perform poorly could be referred for a treatment trial or more formal testing. In addition, collaboration with a psychologist for evaluation of these results or for further detailed testing may be needed for clinicians who require further interpretation and guidance

\section{OHE: DIAGNOSIS}

The diagnostic strategies for $\mathrm{OHE}$ are inconsistent given its subjectivity, and thus require careful attention in each case. Traditionally OHE severity is graded by the $\mathrm{WHC}^{14}$, which now consists of stages $2-4$ in the new classification. OHE is usually associated with a precipitating factor(s) such as: gastrointestinal bleeding, acute kidney injury, infection, constipation, electrolyte imbalances, and other forms of liver injury (alcoholic injury, portal vein thrombosis, hepatocellular carcinoma). OHE must be differentiated from other neurological diseases such as acute cerebro-vascular accidents (CVA), alcohol-related issues, and other forms of metabolic encephalopathy.

Clinically, patients with OHE demonstrate global neurological deficits. In stages 2-3, motor system abnormalities are clinically apparent. These include hyper-reflexia, hypertonia, asterixis, bradykinesias, rigidity, tremors, and ataxia. Note that asterixis is not pathognomonic for OHE as it can observed in other disease processes such as hypercarbia and uremia ${ }^{8}$. Mentally (either behaviorally or cognitively), patients may be aggressive, agitated, disoriented to time and place, display bizarre behavior, have personality changes, have slurred speech, lethargic or apathetic. In stage 4, patients are comatose and examination will reveal diminished or absent deep tendon reflexes, with the presence of pyramidal tract signs without asterixis.

Currently there are no "gold standard" laboratory markers that can be used to diagnose OHE but rather are useful to define precipitating factors or alternative explanations for altered mental status. While elevated blood ammonia levels are often found in OHE in large population studies, in an individual patient however, it is often not useful as a diagnostic tes $^{38}$. On the other hand, a normal ammonia level in a cirrhotic with altered mental status should question the diagnosis of $\mathrm{OHE}^{3}$. In addition, venous ammonia levels are influenced by multiple factors, including how the sample was collected: the use of a tourniquet, fist clenching, and whether the sample is placed immediately on ice ${ }^{38}$. Lastly, though not routinely recommended as a diagnostic tool for $\mathrm{HE}$, brain imaging $\left(\mathrm{CT}\right.$ and $\left.\mathrm{MRI}^{39}\right)$ can help exclude other intracranial pathology. 


\section{MANAGEMENT OF CHE AND OHE}

The treatment and management of HE depend on its severity and acuity. Patients with CHE are mostly managed as an outpatient using non-absorbable disaccharides, antibiotics (i.e. rifaximin) and other agents. Based on its severity, OHE can be managed both as outpatient or inpatient with similar agents. Goals of therapy for CHE include the prevention of OHE and OHE-related hospitalizations, improve HRQOL, prevent hospitalizations, and mortality. The goals of therapy for OHE episodes are to diagnose and treat the inciting factor, as up to $90 \%$ of patients will have a precipitant ${ }^{40}$, and improve mental status. In addition, after an episode of OHE, therapy should also be directed in preventing recurrence, improve HRQOL, and consideration for liver transplant. A focus should also be directed on patient and family member education on the disease progression and adherence to medications. An algorithm for the management of CHE and OHE can be found on Figure 2.

The treatments are studied in the context of
A. CHE
B. Episode of OHE
C. Secondary prevention of OHE

\section{Overview of medications for HE therapy}

Non-absorbable Disaccharides—Lactulose and lactitol are common non-absorbable disaccharides used for HE treatment. When administered, they are degraded by microbiota in the colon to short chain organic acids creating both an acidic environment and an osmotic gradient in the intestinal lumen ${ }^{20}$. The acidic environment created is hypothesized to reduce ammoniagenic bacteria and convert ammonia to non-absorbable ammonium. In addition, the increased osmolality also causes intestinal cleansing via removal of excess fecal nitrogen through a laxative effect ${ }^{20}$.

Lactulose is the most used disaccharide for the treatment of HE. It is usually administered as an oral syrup with dosages titrated for a goal of $2-4$ soft bowel movements a day ${ }^{20}$. Lactulose can also be given rectally ( $300 \mathrm{ml}$ in $700 \mathrm{ml}$ of saline), which is preferred in those in whom oral administration is contraindicated (Grade 3 or higher WHC). Common sideeffects of lactulose include flatulence, abdominal discomfort, and diarrhea. Lactitol (which is not available in the US) is a crystalline powder that is generally better tolerated and as efficacious as lactulose ${ }^{20}$.

Antibiotics-The rationale of using antibiotics for HE is to prevent the production and absorption of gut-derived neurotoxins, such as ammonia, along with reduction in endotoxemia and inflammation ${ }^{41}$. Antibiotics that been studied include neomycin, metronidazole, vancomycin, paromomycin, and rifaximin, although only rifaximin remains in regular usage in the US.

For OHE, all the aforementioned antibiotics have been tested. However, inadequate sample size, adverse side-effects (such as ototoxicity and nephrotoxicity of neomycin), and the potential for resistance (vancomycin-resistant enterococcus) has limited their use. An 
exception from these agents is rifaximin, which has the safest side-effect profile and largest evidence base.

Rifaximin is a gut specific, non-absorbable oral antibiotic that has a broad spectrum of activity against both gram positive and gram negative bacteria, and anaerobic enteric bacteria $^{41}$. It binds to the bacterial DNA dependent RNA polymerase and disrupts RNA synthesis. It is approved by the U.S. Food and Drug Administration (FDA) for only secondary prevention of OHE. The most common side-effects reported include flatulence, abdominal pain, headaches, and constipation.

Probiotics-Probiotics are live microbiologic dietary supplements that alter the intestinal balance of microflora in the gut. The mechanism of action of probiotics in HE is thought to be the deprivation of substrates for potentially pathogenic bacteria and providing a healthy environment for beneficial bacteria ${ }^{42}$. At this time, however, neither the mechanism nor the optimum probiotic organism has been identified or have been studied against each other. Adding to the complexity is the lack of standardization of these agents in the US, and that they do not fall under the review of the FDA.

\section{CHE Management}

It is important to note that most studies in CHE did not measure outcomes data such as hospitalizations, OHE prevention, or death. But rather had endpoints such as improvement in HRQOL and cognitive testing.

Numerous controlled trials comparing lactulose or lactitol to placebo have shown improvement in the psychometric and neurophysiologic variables for CHE, but did not show any improvement in mortality $43,44,45,46,47$ (Table 3). In a meta-analysis including 9 randomized controlled trials (RCT) comparing lactulose to placebo or with no intervention, lactulose significantly reduced the risk of no improvement in neuropsychological tests, prevented the progression to OHE, and improved HRQOL ${ }^{48}$. However larger, blinded studies are needed to better analyze this issue.

There is limited evidence for rifaximin in the management of $\mathrm{CHE}^{49,50}$. Rifaximin has been shown to improve the driving ability in patients with CHE and also improve cognition ${ }^{49}$. This was further validated in a study by Sidhu et $\mathrm{al}^{50}$ where the authors concluded rifaximin significantly improved cognitive function and HRQOL. However at the current prices, rifaximin is cost-prohibitive for treatment for $\mathrm{CHE}^{51}$.

Probiotics have shown potential for the management of CHE. In a meta-analysis of 9 studies, the use of probiotics significantly reduced the risk of no improvement of MHE ${ }^{52}$. Furthermore, in a recent open label trial by Lunia et a ${ }^{53}, 3$ month use of probiotics was found to be effective in preventing the first occurrence of OHE and had improved scores in cognitive testing. VSL \#3 probiotics has also shown efficacy for improvement of $\mathrm{CHE}^{54}$ and awaits further validation. Furthermore, probiotics have been found to reduce endotoxemia in patients with CHE. In a phase 1 controlled trial of Lactobacillus GG vs placebo, CHE patients taking Lactobacillus had reduced levels of endotoxemia, TNF-alpha, and dysbiosis ${ }^{55}$. 


\section{OHE Management}

The use of lactulose or lactitol for OHE has been the mainstay of therapy despite its variable efficacy in trials ${ }^{56,57,58,59}$ (Table 3). It should also be noted that these studies were small and underpowered. In a meta-analysis by Als-Nielsen et al ${ }^{60}$, when compared to placebo or no intervention, non-absorbable disaccharides had no statistically significant effect on mortality, but did show to reduce the risk of no improvement of OHE. Thus far there is insufficient evidence that lactulose is efficacious for OHE, however, there is an overwhelming clinical anecdotal experience and comfort for the use of lactulose, which accounts for the lack of placebo RCT for HE.

A number of studies have been performed comparing rifaximin with other antibiotics or lactulose/lactitol in the treatment of OHE (table 4) $61,62,63,64,65,66,67,68,69,68$. Rifaximin has shown to be superior to lactulose and other antibiotics in patients with $\mathrm{OHE}^{70}$. In view of the data, rifaximin has a definite role in the management of OHE and there are trials on the way to further validate its role.

Unlike CHE, the data for probiotics in OHE are inadequate given the sample size, different probiotics used, and questionable duration of treatment. In a Cochrane meta-analysis of 7 $\mathrm{CHE} / \mathrm{OHE}$ trials $^{71}$ there were no reported differences of probiotics compared to lactulose with respect to reduction in ammonia levels and improvement in mental status. The analysis did show an advantage of probiotics to no treatment in all-cause mortality, number of adverse events, and HRQOL.

\section{Secondary Prevention of OHE}

Data for nonabsorbable disaccharides for secondary prevention for OHE have been sparse. In an open labeled RCT, Sharma et al ${ }^{72}$ showed that lactulose was able to prevent recurrent OHE. However, in the real-world this is often not tolerated in the US population, where $46 \%$ of recurrences were due to lactulose misuse ${ }^{73}$.

Bass et ${ }^{68}$ al showed that rifaximin (vs. placebo, $>90 \%$ on lactulose) was more effective in preventing OHE over 6 months compared to placebo. In a follow up long term open label study, rifaximin continued to provide a reduction in the rate of HE-related and all-cause hospitalizations, without an increased rate of adverse events ${ }^{74}$. This was further validated by Bajaj et al ${ }^{75}$ in a placebo cross-over sub-analysis. Furthermore, in a recent meta-analysis ${ }^{76}$ that included 19 RCT with 1370 patients, rifaximin was found to have a beneficial effect on secondary prevention of OHE, increased the proportion of patients who recovered from $\mathrm{OHE}$, and reduced mortality.

Probiotics have also been studied for secondary prevention. In an open-labeled trial ${ }^{77}$, VSL\#3 was found to be similar to lactulose for secondary prevention. This was confirmed in a double-blind, randomized VSL\#3 trial $^{78}$ where the VSL\#3 arm resulted in significant reduction in recurrent OHE episodes and hospitalizations, all-cause hospitalizations, and had improved cirrhosis severity. The use of probiotics still needs validation in terms of which specific organism(s) are to be used and ensuring pharmaceutical-grade products --which are often unavailable. 


\section{Other therapies}

\section{L-Ornithine-L-Aspartate, Ornithine Phenylacetate, and Glycerol}

Phenylbutyrate-L-ornithine-L-aspartate (LOLA, not available in the US) can reduce blood ammonia levels via stimulating both the urea cycle and glutamine synthesis ${ }^{19}$. It has been studied extensively with better results with its intravenous rather than oral formulation across the HE spectrum ${ }^{79,80,81,82,83,84}$.

Ornithine phenylacetate (OP) ${ }^{85}$ and glycerol phenylbutyrate (GP) ${ }^{86}$ are drugs that have shown to reduce ammonia levels and promise for the treatment of both OHE and secondary prevention. Further trials are underway for both OP and GP in the management of HE.

Zinc-Low levels of zinc leads to impairment of the urea cycle enzymes and glutamine synthetase, thus leading to elevated ammonia levels ${ }^{19}$. Zinc supplementation for the treatment for $\mathrm{HE}$ has been limited given the small number of trials and subjects, however, results from these studies have shown decreased ammonia levels and an improvement in cognitive testing ${ }^{87}$. Thus, the current role of zinc supplementation is in patients who are zinc deficient and who are resistant to usual therapy for HE.

Albumin and Albumin Dialysis-Albumin infusion and using albumin dialysis (i.e. molecular adsorbent recirculating system, MARS) has been observed for the treatment of OHE. In a small trial of 56 patients $^{88}$, albumin infusion did not show faster resolution of OHE, but unexpectedly showed a mortality benefit in the albumin treated group. MARS dialysis has shown to improve $\mathrm{OHE}^{89}$ and refractory $\mathrm{HE}^{90}$, though there was no survival benefit seen.

Miscellaneous Agents-Other agents such as sodium benzoate, levocarnitine, acarbose, benzodiazepine receptor antagonists, have no significant role in the management of CHE and OHE given limited recent trial data ${ }^{8}$.

\section{NUTRITIONAL MANAGEMENT}

The AASLD and ISHEN recommends that patients with cirrhosis should have $1.2 \mathrm{~g} / \mathrm{kg}$ to $1.5 \mathrm{~g} / \mathrm{kg}$ of protein daily to maintain muscle mass ${ }^{3,91}$. In addition, increasing intake of branched-chain amino acids (BCAAs) may be beneficial for HE, but did not show any mortality benefit and improvement in HRQOL. BCAA's are not readily available in the US.

\section{MANAGEMENT OF REFRACTORY HE}

There are rare instances where a patient will have continued recurrences of OHE despite optimal medical management and compliance. Here it is imperative to search for other possible reasons such as spontaneous portosystemic shunts (Figure 2). In those patients in whom HE does not improve despite aggressive medical therapies, liver transplant is the definitive treatment. 


\section{FUTURE DIRECTIONS}

Future directions for the study of HE includes convenient, rapid, and validated methods to diagnose CHE, as well as better objective methods to diagnose the severity of OHE. This is paramount as early recognition could impact morbidity and mortality, and HRQOL. At this time therapy for CHE can be used in selected cases for psychosocial purposes as further trials are needed to substantiate the role of therapy in routine clinical practice. Clinicians should also be meticulous in the management of patient after an episode of OHE, by helping preventing further episodes, liver transplant evaluation, and education on how to administer their medication. There are numerous newer agents under study to add to our armamentarium.

\section{Acknowledgments}

Grant support: This paper was partly supported by VA Merit Review CX001076, RO1AA020203 from the National Institute on Alcohol Abuse and Alcoholism, by grant RO1DK087913 from the National Institute of Diabetes and Digestive and Kidney Diseases

\section{Listing of Abbreviations}

$\begin{array}{ll}\text { HE } & \text { hepatic encephalopathy } \\ \text { CHE } & \text { covert hepatic encephalopathy } \\ \text { OHE } & \text { overt hepatic encephalopathy } \\ \text { SONIC } & \text { spectrum of neurocognitive impairment in cirrhosis } \\ \text { MELD, HRQOL } & \text { health related quality of life } \\ \text { MELD } & \text { model for end-stage liver disease } \\ \text { BBB } & \text { blood brain barrier } \\ \text { IL } & \text { interleukin } \\ \text { TNF } & \text { tumor necrosis factor } \\ \text { GABA } & \gamma \text {-aminobutyric acid benzodiazepine system } \\ \text { WHC } & \text { west haven criteria } \\ \text { PHES } & \text { psychometric hepatic encephalopathy score } \\ \text { NCT-A } & \text { number connection test } \\ \text { ISHEN } & \text { International Society for Hepatic Encephalopahty and Nitrogen } \\ & \text { Metabolism } \\ \text { RBANS } & \text { the Repeatable Battery for the Assessment of Neuropsychological } \\ \text { ICT } & \text { Status } \\ \text { CDR } & \text { inhibitory control test } \\ \text { AUC } & \text { cognitive drug research } \\ \end{array}$


EEG

CFF

CVA

RCT

FDA

LOLA

OP

GP

MARS

AASLD

BCAA's electroencephalography

critical flicker frequency

cerebro-vascular accidents

randomized controlled trials

Food and Drug Administration (FDA)

L-ornithine-L-aspartate

Ornithine phenylacetate

glycerol phenylbutyrate

molecular adsorbent recirculating system

American Association For the Study of Liver Disease

Branched-chain amino acids

\section{Reference}

1. Bustamante J, Rimola A, Ventura PJ, et al. Prognostic significance of hepatic encephalopathy in patients with cirrhosis. J Hepatol. 1999; 30:890-895. [PubMed: 10365817]

2. Ferenci P, Lockwood A, Mullen K, et al. Hepatic encephalopathy--definition, nomenclature, diagnosis, and quantification: final report of the working party at the 11th World Congresses of Gastroenterology, Vienna, 1998. Hepatology. 2002; 35:716-721. [PubMed: 11870389]

3. Vilstrup H, Amodio P, Bajaj J, et al. Hepatic encephalopathy in chronic liver disease: 2014 Practice Guideline by the American Association for the Study of Liver Diseases and the European Association for the Study of the Liver. Hepatology. 2014; 60:715-735. [PubMed: 25042402]

4. Bajaj JS, Cordoba J, Mullen KD, et al. Review article: the design of clinical trials in hepatic encephalopathy--an International Society for Hepatic Encephalopathy and Nitrogen Metabolism (ISHEN) consensus statement. Aliment Pharmacol Ther. 2011; 33:739-747. [PubMed: 21306407]

5. Bajaj JS, Wade JB, Sanyal AJ. Spectrum of neurocognitive impairment in cirrhosis: Implications for the assessment of hepatic encephalopathy. Hepatology. 2009; 50:2014-2021. [PubMed: 19787808]

6. Das A, Dhiman RK, Saraswat VA, et al. Prevalence and natural history of subclinical hepatic encephalopathy in cirrhosis. J Gastroenterol Hepatol. 2001; 16:531-535. [PubMed: 11350549]

7. Ortiz M, Jacas C, Cordoba J. Minimal hepatic encephalopathy: diagnosis, clinical significance and recommendations. J Hepatol. 2005; 42(Suppl):S45-S53. [PubMed: 15777572]

8. Bajaj JS. Review article: the modern management of hepatic encephalopathy. Aliment Pharmacol Ther. 2010; 31:537-547. [PubMed: 20002027]

9. Stepanova M, Mishra A, Venkatesan C, et al. In-hospital mortality and economic burden associated with hepatic encephalopathy in the United States from 2005 to 2009. Clin Gastroenterol Hepatol. 2012; 10:1034-41.e1. [PubMed: 22642955]

10. Poordad FF. Review article: the burden of hepatic encephalopathy. Aliment Pharmacol Ther. 2007; 25(Suppl 1):3-9. [PubMed: 17295846]

11. Arguedas MR, DeLawrence TG, McGuire BM. Influence of hepatic encephalopathy on healthrelated quality of life in patients with cirrhosis. Dig Dis Sci. 2003; 48:1622-1626. [PubMed: 12924658]

12. Stewart CA, Malinchoc M, Kim WR, et al. Hepatic encephalopathy as a predictor of survival in patients with end-stage liver disease. Liver Transpl. 2007; 13:1366-1371. [PubMed: 17520742]

13. Wong RJ, Gish RG, Ahmed A. Hepatic encephalopathy is associated with significantly increased mortality among patients awaiting liver transplantation. Liver Transpl. 2014; 20:1454-1461.

[PubMed: 25155379] 
14. Conn HO, Leevy CM, Vlahcevic ZR, et al. Comparison of lactulose neomycin in the treatment of chronic portal-systemic encephalopathy. A double blind controlled trial. Gastroenterology. 1977; 72:573-583. [PubMed: 14049]

15. Dhiman RK, Sawhney MS, Chawla YK, et al. Efficacy of lactulose in cirrhotic patients with subclinical hepatic encephalopathy. Dig Dis Sci. 2000; 45:1549-1552. [PubMed: 11007104]

16. Groeneweg M, Quero JC, De Bruijn I, et al. Subclinical hepatic encephalopathy impairs daily functioning. Hepatology. 1998; 28:45-49. [PubMed: 9657095]

17. Bajaj JS, Hafeezullah M, Franco J, et al. Inhibitory control test for the diagnosis of minimal hepatic encephalopathy. Gastroenterology. 2008; 135:1591-1600.e1. [PubMed: 18723018]

18. Patidar KR, Thacker LR, Wade JB, et al. Covert hepatic encephalopathy is independently associated with poor survival and increased risk of hospitalization. Am J Gastroenterol. 2014; 109:1757-1763. [PubMed: 25178701]

19. Sundaram V, Shaikh OS. Hepatic encephalopathy: pathophysiology and emerging therapies. Med Clin North Am. 2009; 93:819-836. vii. [PubMed: 19577116]

20. Gerber T, Schomerus H. Hepatic encephalopathy in liver cirrhosis: pathogenesis, diagnosis and management. Drugs. 2000; 60:1353-1370. [PubMed: 11152016]

21. Ott P, Larsen FS. Blood-brain barrier permeability to ammonia in liver failure: a critical reappraisal. Neurochem Int. 2004; 44:185-198. [PubMed: 14602081]

22. Haussinger D, Kircheis G, Fischer R, et al. Hepatic encephalopathy in chronic liver disease: a clinical manifestation of astrocyte swelling and low-grade cerebral edema? J Hepatol. 2000; 32:1035-1038. [PubMed: 10898326]

23. Palomero-Gallagher N, Zilles K. Neurotransmitter receptor alterations in hepatic encephalopathy: a review. Arch Biochem Biophys. 2013; 536:109-121. [PubMed: 23466244]

24. Bajaj JS. The role of microbiota in hepatic encephalopathy. Gut Microbes. 2014; 5:397-403. [PubMed: 24690956]

25. Shawcross DL, Davies NA, Williams R, et al. Systemic inflammatory response exacerbates the neuropsychological effects of induced hyperammonemia in cirrhosis. J Hepatol. 2004; 40:247254. [PubMed: 14739095]

26. Cordoba J. New assessment of hepatic encephalopathy. J Hepatol. 2011; 54:1030-1040. [PubMed: 21145874]

27. Randolph C, Hilsabeck R, Kato A, et al. Neuropsychological assessment of hepatic encephalopathy: ISHEN practice guidelines. Liver Int. 2009; 29:629-635. [PubMed: 19302444]

28. Goldbecker A, Weissenborn K, Hamidi Shahrezaei G, et al. Comparison of the most favoured methods for the diagnosis of hepatic encephalopathy in liver transplantation candidates. Gut. 2013; 62:1497-1504. [PubMed: 23297006]

29. Bajaj JS, Hafeezullah M, Franco J, et al. Inhibitory control test for the diagnosis of minimal hepatic encephalopathy. Gastroenterology. 2008; 135:1591-1600.e1. [PubMed: 18723018]

30. Mardini H, Saxby BK, Record CO. Computerized psychometric testing in minimal encephalopathy and modulation by nitrogen challenge and liver transplant. Gastroenterology. 2008; 135:15821590. [PubMed: 18647604]

31. Bajaj JS, Thacker LR, Heuman DM, et al. The Stroop smartphone application is a short and valid method to screen for minimal hepatic encephalopathy. Hepatology. 2013; 58:1122-1132. [PubMed: 23389962]

32. Bajaj JS, Heuman DM, Sterling RK, et al. Validation of EncephalApp, Smartphone-Based Stroop Test, for the Diagnosis of Covert Hepatic Encephalopathy. Clin Gastroenterol Hepatol. 2014 S1542-S3565(14)00749-6.

33. Amodio P, Pellegrini A, Ubiali E, et al. The EEG assessment of low-grade hepatic encephalopathy: comparison of an artificial neural network-expert system (ANNES) based evaluation with visual EEG readings and EEG spectral analysis. Clin Neurophysiol. 2006; 117:2243-2251. [PubMed: 16931145]

34. Montagnese S, Amodio P, Morgan MY. Methods for diagnosing hepatic encephalopathy in patients with cirrhosis: a multidimensional approach. Metab Brain Dis. 2004; 19:281-312. [PubMed: 15554423] 
35. Kircheis G, Wettstein M, Timmermann L, et al. Critical flicker frequency for quantification of lowgrade hepatic encephalopathy. Hepatology. 2002; 35:357-366. [PubMed: 11826409]

36. Sharma P, Sharma BC, Sarin SK. Critical flicker frequency for diagnosis and assessment of recovery from minimal hepatic encephalopathy in patients with cirrhosis. Hepatobiliary Pancreat Dis Int. 2010; 9:27-32. [PubMed: 20133225]

37. Nabi E, Thacker LR, Wade JB, et al. Diagnosis of covert hepatic encephalopathy without specialized tests. Clin Gastroenterol Hepatol. 2014; 12:1384-1389.e2. [PubMed: 24362049]

38. Ge PS, Runyon BA. Serum ammonia level for the evaluation of hepatic encephalopathy. JAMA. 2014; 312:643-644. [PubMed: 25117134]

39. Grover VP, Dresner MA, Forton DM, et al. Current and future applications of magnetic resonance imaging and spectroscopy of the brain in hepatic encephalopathy. World J Gastroenterol. 2006; 12:2969-2978. [PubMed: 16718775]

40. Strauss E, Tramote R, Silva EP, et al. Double-blind randomized clinical trial comparing neomycin and placebo in the treatment of exogenous hepatic encephalopathy. Hepatogastroenterology. 1992; 39:542-545. [PubMed: 1483668]

41. Patidar KR, Bajaj JS. Antibiotics for the treatment of hepatic encephalopathy. Metab Brain Dis. 2013; 28:307-312. [PubMed: 23389621]

42. Solga SF. Probiotics can treat hepatic encephalopathy. Med Hypotheses. 2003; 61:307-313. [PubMed: 12888324]

43. Horsmans Y, Solbreux PM, Daenens C, et al. Lactulose improves psychometric testing in cirrhotic patients with subclinical encephalopathy. Aliment Pharmacol Ther. 1997; 11:165-170. [PubMed: 9042989]

44. Watanabe A, Sakai T, Sato S, et al. Clinical efficacy of lactulose in cirrhotic patients with and without subclinical hepatic encephalopathy. Hepatology. 1997; 26:1410-1414. [PubMed: 9397979]

45. Dhiman RK, Sawhney MS, Chawla YK, et al. Efficacy of lactulose in cirrhotic patients with subclinical hepatic encephalopathy. Dig Dis Sci. 2000; 45:1549-1552. [PubMed: 11007104]

46. Prasad S, Dhiman RK, Duseja A, et al. Lactulose improves cognitive functions and health-related quality of life in patients with cirrhosis who have minimal hepatic encephalopathy. Hepatology. 2007; 45:549-559. [PubMed: 17326150]

47. Sharma P, Sharma BC, Puri V, et al. An open-label randomized controlled trial of lactulose and probiotics in the treatment of minimal hepatic encephalopathy. Eur J Gastroenterol Hepatol. 2008; 20:506-511. [PubMed: 18467909]

48. Luo M, Li L, Lu CZ, et al. Clinical efficacy and safety of lactulose for minimal hepatic encephalopathy: a meta-analysis. Eur J Gastroenterol Hepatol. 2011; 23:1250-1257. [PubMed: 21971378]

49. Bajaj JS, Heuman DM, Wade JB, et al. Rifaximin improves driving simulator performance in a randomized trial of patients with minimal hepatic encephalopathy. Gastroenterology. 2011; 140:478-487.e1. [PubMed: 20849805]

50. Sidhu SS, Goyal O, Mishra BP, et al. Rifaximin improves psychometric performance and healthrelated quality of life in patients with minimal hepatic encephalopathy (the RIME Trial). Am J Gastroenterol. 2011; 106:307-316. [PubMed: 21157444]

51. Bajaj JS, Pinkerton SD, Sanyal AJ, et al. Diagnosis and treatment of minimal hepatic encephalopathy to prevent motor vehicle accidents: a cost-effectiveness analysis. Hepatology. 2012; 55:1164-1171. [PubMed: 22135042]

52. Shukla S, Shukla A, Mehboob S, et al. Meta-analysis: the effects of gut flora modulation using prebiotics, probiotics and synbiotics on minimal hepatic encephalopathy. Aliment Pharmacol Ther. 2011; 33:662-671. [PubMed: 21251030]

53. Lunia MK, Sharma BC, Sharma P, et al. Probiotics prevent hepatic encephalopathy in patients with cirrhosis: a randomized controlled trial. Clin Gastroenterol Hepatol. 2014; 12 1003-8.e1.

54. Pratap Mouli V, Benjamin J, Bhushan Singh M, et al. Effect of probiotic VSL\#3 in the treatment of minimal hepatic encephalopathy: A non-inferiority randomized controlled trial. Hepatol Res. 2014 
55. Bajaj JS, Heuman DM, Hylemon PB, et al. Randomised clinical trial: Lactobacillus GG modulates gut microbiome, metabolome and endotoxemia in patients with cirrhosis. Aliment Pharmacol Ther. 2014; 39:1113-1125. [PubMed: 24628464]

56. Simmons F, Goldstein H, Boyle JD. A controlled clinical trial of lactulose in hepatic encephalopathy. Gastroenterology. 1970; 59:827-832. [PubMed: 4922276]

57. Rodgers JB Jr, Kiley JE, Balint JA. Comparison of results of long-term treatment of chronic hepatic encephalopathy with lactulose and sorbitol. Am J Gastroenterol. 1973; 60:459-465. [PubMed: 4587191]

58. Uribe M, Campollo O, Vargas F, et al. Acidifying enemas (lactitol, lactose) vs. nonacidifying enemas (tap water) to treat acute portal-systemic encephalopathy: a double-blind, randomized clinical trial. Hepatology. 1987; 7:639-643. [PubMed: 3301614]

59. Elkington SG, Floch MH, Conn HO. Lactulose in the treatment of chronic portal-systemic encephalopathy. A double-blind clinical trial. N Engl J Med. 1969; 281:408-412. [PubMed: 4894464]

60. Als-Nielsen B, Gluud LL, Gluud C. Nonabsorbable disaccharides for hepatic encephalopathy. Cochrane Database Syst Rev. 2004; (2) CD003044.

61. Festi D, Mazzella G, Orsini M, et al. Rifaximin in the treatment of chronic hepatic encephalopathy: Results of a multicenter study of efficacy and safety. Curr Ther Res Clin Exp. 1993; 54:598-609.

62. Bucci L, Palmieri GC. Double-blind, double-dummy comparison between treatment with rifaximin and lactulose in patients with medium to severe degree hepatic encephalopathy. Curr Med Res Opin. 1993; 13:109-118. [PubMed: 8325041]

63. Massa P, Vallerino E, Dodero M. Treatment of hepatic encephalopathy with rifaximin: doubleblind, double-dummy study versus lactulose. Eur J Clin Res. 1993; 4:7-18.

64. Fera G, Agostinacchio F, Nigro M, et al. Rifaximin in the treatment of hepatic encephalopathy. Eur J Clin Res. 1993; 4(1):57-66.

65. Mas A, Rodes J, Sunyer L, et al. Comparison of rifaximin and lactitol in the treatment of acute hepatic encephalopathy: results of a randomized, double-blind, double-dummy, controlled clinical trial. J Hepatol. 2003; 38:51-58. [PubMed: 12480560]

66. Leevy CB, Phillips JA. Hospitalizations during the use of rifaximin versus lactulose for the treatment of hepatic encephalopathy. Dig Dis Sci. 2007; 52:737-741. [PubMed: 17245628]

67. Paik YH, Lee KS, Han KH, et al. Comparison of rifaximin and lactulose for the treatment of hepatic encephalopathy: a prospective randomized study. Yonsei Med J. 2005; 46:399-407. [PubMed: 15988813]

68. Bass NM, Mullen KD, Sanyal A, et al. Rifaximin treatment in hepatic encephalopathy. N Engl J Med. 2010; 362:1071-1081. [PubMed: 20335583]

69. Sharma BC, Sharma P, Lunia MK, et al. A randomized, double-blind, controlled trial comparing rifaximin plus lactulose with lactulose alone in treatment of overt hepatic encephalopathy. Am J Gastroenterol. 2013; 108:1458-1463. [PubMed: 23877348]

70. Bajaj JS, Riggio O. Drug therapy: rifaximin. Hepatology. 2010; 52:1484-1488. [PubMed: 20814894]

71. McGee RG, Bakens A, Wiley K, et al. Probiotics for patients with hepatic encephalopathy. Cochrane Database Syst Rev. 2011; (11) CD008716.

72. Sharma BC, Sharma P, Agrawal A, et al. Secondary prophylaxis of hepatic encephalopathy: an open-label randomized controlled trial of lactulose versus placebo. Gastroenterology. 2009; 137:885-891. 891.e1. [PubMed: 19501587]

73. Bajaj JS, Sanyal AJ, Bell D, et al. Predictors of the recurrence of hepatic encephalopathy in lactulose-treated patients. Aliment Pharmacol Ther. 2010; 31:1012-1017. [PubMed: 20136802]

74. Mullen KD, Sanyal AJ, Bass NM, et al. Rifaximin is safe and well tolerated for long-term maintenance of remission from overt hepatic encephalopathy. Clin Gastroenterol Hepatol. 2014; 12 1390-7.e2.

75. Bajaj JS, Barrett AC, Bortey E, et al. Prolonged remission from hepatic encephalopathy with rifaximin: results of a placebo crossover analysis. Aliment Pharmacol Ther. 2015; 41:39-45. [PubMed: 25339518] 
76. Kimer N, Krag A, Moller S, et al. Systematic review with meta-analysis: the effects of rifaximin in hepatic encephalopathy. Aliment Pharmacol Ther. 2014; 40:123-132. [PubMed: 24849268]

77. Agrawal A, Sharma BC, Sharma P, et al. Secondary prophylaxis of hepatic encephalopathy in cirrhosis: an open-label, randomized controlled trial of lactulose, probiotics, and no therapy. Am J Gastroenterol. 2012; 107:1043-1050. [PubMed: 22710579]

78. Dhiman RK, Rana B, Agrawal S, et al. Probiotic VSL\#3 reduces liver disease severity and hospitalization in patients with cirrhosis: a randomized, controlled trial. Gastroenterology. 2014; 147 1327-37.e3.

79. Stauch S, Kircheis G, Adler G, et al. Oral L-ornithine-L-aspartate therapy of chronic hepatic encephalopathy: results of a placebo-controlled double-blind study. J Hepatol. 1998; 28:856-864. [PubMed: 9625322]

80. Kircheis G, Nilius R, Held C, et al. Therapeutic efficacy of L-ornithine-L-aspartate infusions in patients with cirrhosis and hepatic encephalopathy: results of a placebo-controlled, double-blind study. Hepatology. 1997; 25:1351-1360. [PubMed: 9185752]

81. Mittal VV, Sharma BC, Sharma P, et al. A randomized controlled trial comparing lactulose, probiotics, and L-ornithine L-aspartate in treatment of minimal hepatic encephalopathy. Eur J Gastroenterol Hepatol. 2011; 23:725-732. [PubMed: 21646910]

82. Poo JL, Gongora J, Sanchez-Avila F, et al. Efficacy of oral L-ornithine-L-aspartate in cirrhotic patients with hyperammonemic hepatic encephalopathy. Results of a randomized, lactulosecontrolled study. Ann Hepatol. 2006; 5:281-288. [PubMed: 17151582]

83. Sharma K, Pant S, Misra S, et al. Effect of rifaximin, probiotics, and 1-ornithine 1-aspartate on minimal hepatic encephalopathy: a randomized controlled trial. Saudi J Gastroenterol. 2014; 20:225-232. [PubMed: 25038208]

84. Alvares-da-Silva MR, de Araujo A, Vicenzi JR, et al. Oral 1-ornithine-1-aspartate in minimal hepatic encephalopathy: A randomized, double-blind, placebo-controlled trial. Hepatol Res. 2014; 44:956-963. [PubMed: 24033861]

85. Jalan R, Wright G, Davies NA, Hodges SJ. L-Ornithine phenylacetate (OP): a novel treatment for hyperammonemia and hepatic encephalopathy. Med Hypotheses. 2007; 69:1064-1069. [PubMed: 17467190]

86. Ventura-Cots M, Arranz JA, Simon-Talero M, et al. Safety of ornithine phenylacetate in cirrhotic decompensated patients: an open-label, dose-escalating, single-cohort study. J Clin Gastroenterol. 2013; 47:881-887. [PubMed: 23751856]

87. Chavez-Tapia NC, Cesar-Arce A, Barrientos-Gutierrez T, et al. A systematic review and metaanalysis of the use of oral zinc in the treatment of hepatic encephalopathy. Nutr J. 2013; 12 74-2891-12-74.

88. Simon-Talero M, Garcia-Martinez R, Torrens M, et al. Effects of intravenous albumin in patients with cirrhosis and episodic hepatic encephalopathy: a randomized double-blind study. J Hepatol. 2013; 59:1184-1192. [PubMed: 23872605]

89. Sen S, Davies NA, Mookerjee RP, et al. Pathophysiological effects of albumin dialysis in acute-onchronic liver failure: a randomized controlled study. Liver Transpl. 2004; 10:1109-1119. [PubMed: 15350001]

90. Hassanein TI, Tofteng F, Brown RS Jr, et al. Randomized controlled study of extracorporeal albumin dialysis for hepatic encephalopathy in advanced cirrhosis. Hepatology. 2007; 46:18531862. [PubMed: 17975845]

91. Amodio P, Bemeur C, Butterworth R, et al. The nutritional management of hepatic encephalopathy in patients with cirrhosis: International Society for Hepatic Encephalopathy and Nitrogen Metabolism Consensus. Hepatology. 2013; 58:325-336. [PubMed: 23471642] 


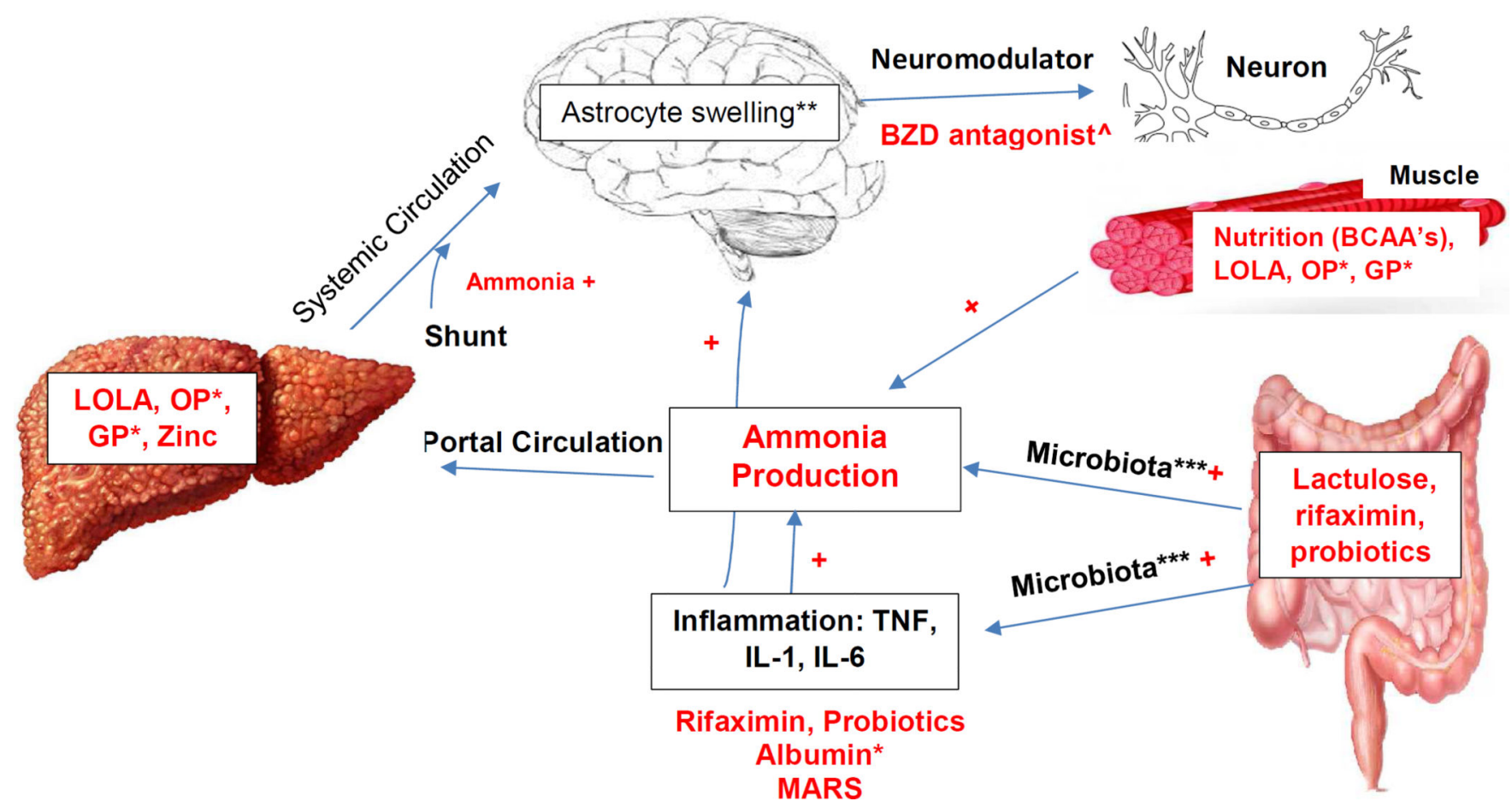

FIGURE 1. Pathophysiology and Potential Therapeutic Targets of Hepatic Encephalopathy *Experimental therapy

** In the brain, astrocytes metabolize ammonia through glutamine synthetase, converting glutamate and ammonia to glutamine which is osmotically active. Increased levels of ammonia leads to an increased production of glutamine which changes the osmotic gradient and causes intracellular swelling and edema. In addition, neurons may be affected by increased "GABAergic tone" from synthesis of benzodiazepine like compounds from the intestinal flora.

***Microbiota may be responsible for the formation or release of products such as ammonia, endotoxins, indoles, oxindoles, and other gut derived toxins that may lead to cognitive impairment.

^Flumazenil (not currently used)

+ Contributing factors

LOLA, L-ornithine L-aspartate; OP, Ornithine -phenylacetate; GP, Glycerol phenylbutyrate; TNF, tumor necrosis factor; IL, interleukin; BZD, benzodiazepine receptor antagonist 


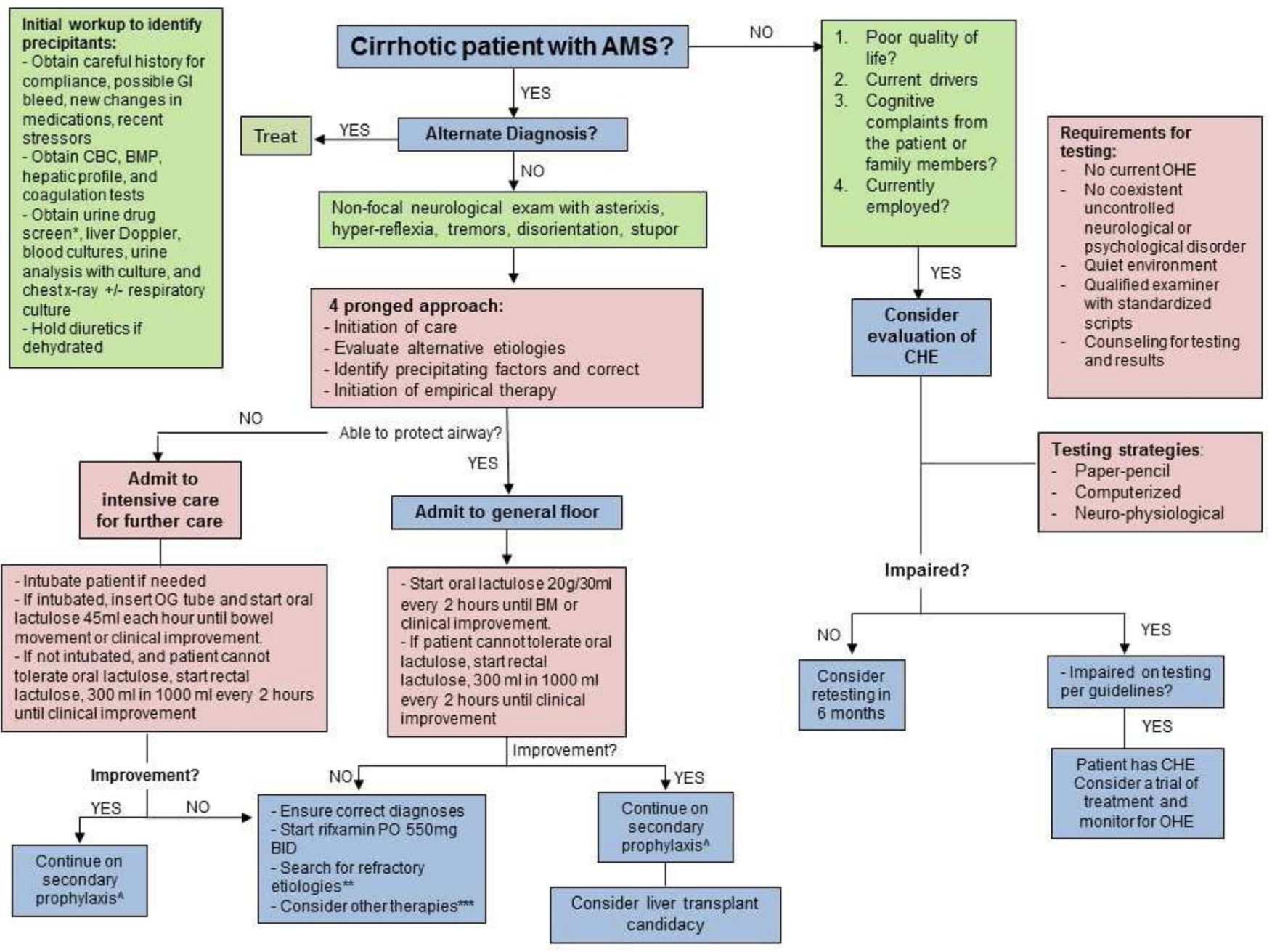

FIGURE 2. Management of Covert and Overt Hepatic Encephalopathy

* if suspicious based on history

** Potential reasons for refractory HE: worsening of liver disease only, failure to identify infection and dehydration, ileus, long acting sedative drug use, concomitant central nervous system diseases or metabolic diseases (i.e. hypothyroidism), transjugular intrahepatic portosystemic shunt dysfunction or supra-therapeutic shunt diameter (if present), profound zinc deficiency, and spontaneous portosystemic shunts.

***Zinc supplementation, LOLA (if available), IV albumin and albumin dialysis, Ornithine phenylacetate, Glycerol phenylbutyrate, spontaneous porto-systemic shunts

${ }^{\wedge}$ Maintenance therapy: 1) lactulose titrated to 2-3 soft BM a day; if intolerant of lactulose start rifaximin 550mg PO BID 2) If > 2 overt episodes start both lactulose and rifaximin; ensure compliance with lactulose along with education (an re-education).

AMS, altered mental status; GI, gastrointestinal; BM, bowel movement; CBC, complete blood count; BMP, basic metabolic panel; OG, oral gastric; $\mathrm{CHE}$, covert hepatic encephalopathy; OHE, overt hepatic encephalopathy 
TABLE 1

Modified Axes of Hepatic Encephalopathy

\begin{tabular}{|c|c|c|c|c|}
\hline Type & \multicolumn{2}{|c|}{ Grade } & Time course & Spont./Precip. \\
\hline \multirow{2}{*}{$\begin{array}{l}\text { A (acute liver } \\
\text { failure) }\end{array}$} & MHE & \multirow{2}{*}{ Covert } & Episodic (one & \multirow{3}{*}{$\begin{array}{l}\text { Spontaneous (no } \\
\text { precipitating factor } \\
\text { found) }\end{array}$} \\
\hline & 1 & & months) & \\
\hline \multirow{2}{*}{$\begin{array}{l}\text { B (porto- } \\
\text { systemic } \\
\text { bypass) }\end{array}$} & 2 & \multirow{2}{*}{ Overt } & \multirow{2}{*}{$\begin{array}{c}\text { Recurrent (>1 } \\
\text { episode in } 6 \\
\text { months) }\end{array}$} & \\
\hline & 3 & & & \multirow[b]{2}{*}{ Precipitated } \\
\hline C (cirrhosis) & 4 & & $\begin{array}{c}\text { Persistent } \\
\text { (never returned } \\
\text { to baseline) }\end{array}$ & \\
\hline
\end{tabular}

Adapted from Vilstrup el al $2014^{3}$ with permission. MHE, minimal Hepatic encephalopathy; Spont, spontaneous; Precip, precipitated 
TABLE 2

Testing for Covert Hepatic Encephalopathy

\begin{tabular}{|c|c|c|c|c|}
\hline $\begin{array}{l}\text { Test (Domains } \\
\text { Examined) }\end{array}$ & Advantages & Disadvantages & Diagnoses & Outcome Prediction \\
\hline \multicolumn{5}{|l|}{ Paper-Pencil } \\
\hline $\begin{array}{l}\text { PHES: NCT-A and B, } \\
\text { digit symbol test, line- } \\
\text { tracing test, and serial- } \\
\text { dotting test (attention, } \\
\text { processing speed, } \\
\text { response inhibition, } \\
\text { and visuo-spatial } \\
\text { awareness) }\end{array}$ & $\begin{array}{l}\text { Validated, gold } \\
\text { standard }\end{array}$ & $\begin{array}{l}\text { Lack of reference } \\
\text { normative data in the } \\
\text { US. }\end{array}$ & Score of $<-4$ & $\begin{array}{c}\text { Score }<-6 \text { predicted poor } \\
\text { survival }\end{array}$ \\
\hline $\begin{array}{l}\text { RBANS (visuo-spatial, } \\
\text { attention, language, } \\
\text { immediate and } \\
\text { delayed memory) }\end{array}$ & $\begin{array}{l}\text { Has US reference } \\
\text { data }\end{array}$ & $\begin{array}{l}\text { Copyrighted, needs } \\
\text { psychologist } \\
\text { interpretation }\end{array}$ & $\begin{array}{l}\text { Dependent on } \\
\text { psychologist } \\
\text { interpretation }\end{array}$ & $\begin{array}{c}\text { not studied in HE; } 2 \\
\text { domains not impaired in } \\
\text { CHE }\end{array}$ \\
\hline \multicolumn{5}{|l|}{ Computerized } \\
\hline $\begin{array}{l}\text { ICT (working memory, } \\
\text { response inhibition, } \\
\text { psychomotor speed) }\end{array}$ & $\begin{array}{l}\text { Validated and } \\
\text { does not require } \\
\text { psychologist } \\
\text { interpretation }\end{array}$ & $\begin{array}{l}\text { Requires high } \\
\text { functioning patients } \\
\text { with working } \\
\text { knowledge of a } \\
\text { computer }\end{array}$ & $\begin{array}{l}\text { high lures or } \\
\text { weighted lures }\end{array}$ & $\begin{array}{l}\text { Significant impairment } \\
\text { leads to increased MV } \\
\text { crashes and violations, } \\
\text { and predicting OHE }\end{array}$ \\
\hline $\begin{array}{l}\text { CDR (attention, } \\
\text { continuity of attention, } \\
\text { speed of memory, and } \\
\text { quality of episodic and } \\
\text { working memory) }\end{array}$ & $\begin{array}{l}\text { Not validated in } \\
\text { US }\end{array}$ & $\begin{array}{l}\text { Requires high } \\
\text { functioning patients } \\
\text { with working } \\
\text { knowledge of a } \\
\text { computer }\end{array}$ & Score of -5 to 15 & $\begin{array}{l}\text { Able to predict resolution } \\
\text { of cognitive dysfunction } \\
\text { post-transplant and TIPS }\end{array}$ \\
\hline $\begin{array}{l}\text { Continuous Reaction } \\
\text { Time (sustained } \\
\text { cerebral processing } \\
\text { time, reaction time and } \\
\text { response inhibition, } \\
\text { and nerve inhibition) }\end{array}$ & $\begin{array}{l}\text { Not validated in } \\
\text { US }\end{array}$ & $\begin{array}{l}\text { Requires adequate } \\
\text { hearing no reference } \\
\text { data for US. }\end{array}$ & CFTindex of $<1.9$ & -- \\
\hline $\begin{array}{l}\text { EncephalApp Stroop } \\
\text { Application } \\
\text { (psychomotor speed, } \\
\text { cognitive flexibility) }\end{array}$ & $\begin{array}{l}\text { Free, and can be } \\
\text { used on a mobile } \\
\text { platform. Has US } \\
\text { reference data }\end{array}$ & $\begin{array}{l}\text { Cannot be done in red- } \\
\text { green color blind } \\
\text { subjects }\end{array}$ & $\begin{array}{l}>190 \text { seconds (on } \\
\text { and off time) }\end{array}$ & $\begin{array}{c}\text { Longer times can predict } \\
\text { OHE episodes }\end{array}$ \\
\hline \multicolumn{5}{|l|}{ Neurophysiological } \\
\hline $\begin{array}{l}\text { EEG (brain activity } \\
\text { mean dominant } \\
\text { frequency) }\end{array}$ & $\begin{array}{l}\text { Can be used on } \\
\text { all stages of } \mathrm{HE} \\
\text { without learning }\end{array}$ & $\begin{array}{l}\text { Highly variable, } \\
\text { requires neurologist } \\
\text { interpretation }\end{array}$ & $\begin{array}{c}\text { Dependent on } \\
\text { neurologist } \\
\text { interpretation }\end{array}$ & $\begin{array}{l}\text { EEG plus MELD } \\
\text { increases accuracy in } \\
\text { predicting prognosis }\end{array}$ \\
\hline $\begin{array}{l}C F F \text { (visual processing } \\
\text { and discrimination, } \\
\text { general arousal) }\end{array}$ & $\begin{array}{l}\text { Test can be } \\
\text { administered at } \\
\text { bedside }\end{array}$ & $\begin{array}{l}\text { Requires high } \\
\text { functioning patients } \\
\text { and expensive } \\
\text { equipment, needs } \\
\text { binocular vision }\end{array}$ & $\mathrm{CFF}<39 \mathrm{~Hz}$ & Can predict $\mathrm{OHE}$ \\
\hline $\begin{array}{l}\text { Evoked potentials } \\
\text { (visual, auditory, and } \\
\text { somatosensory) }\end{array}$ & $\begin{array}{l}\text { Sensitive without } \\
\text { learning effects }\end{array}$ & $\begin{array}{l}\text { High variable results, } \\
\text { requires neurologist } \\
\text { interpretation }\end{array}$ & $\begin{array}{l}\text { Variable, } \\
\text { dependent on } \\
\text { neurologist } \\
\text { interpretation }\end{array}$ & $\begin{array}{c}\text { Can predict the } \\
\text { development of } \mathrm{OHE}\end{array}$ \\
\hline
\end{tabular}

PHES, psychometric hepatic encephalopathy score; NCT, number connection test; RBANS, repeatable battery for the assessment of neuropsychological status; MELD, Model of Endstage Liver disease; ICT, inhibitory control test; CDR, cognitive drug research; EEG, electroencephalography; HE, hepatic encephalopathy; CFF, clicker flicker frequency, OHE, overt hepatic encephalopathy; CTP, Child-TurcottePug; MELD, Model for Endstage Liver Disease; TIPS, transjugular intrahepatic portosystemic shunt 


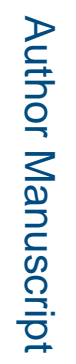

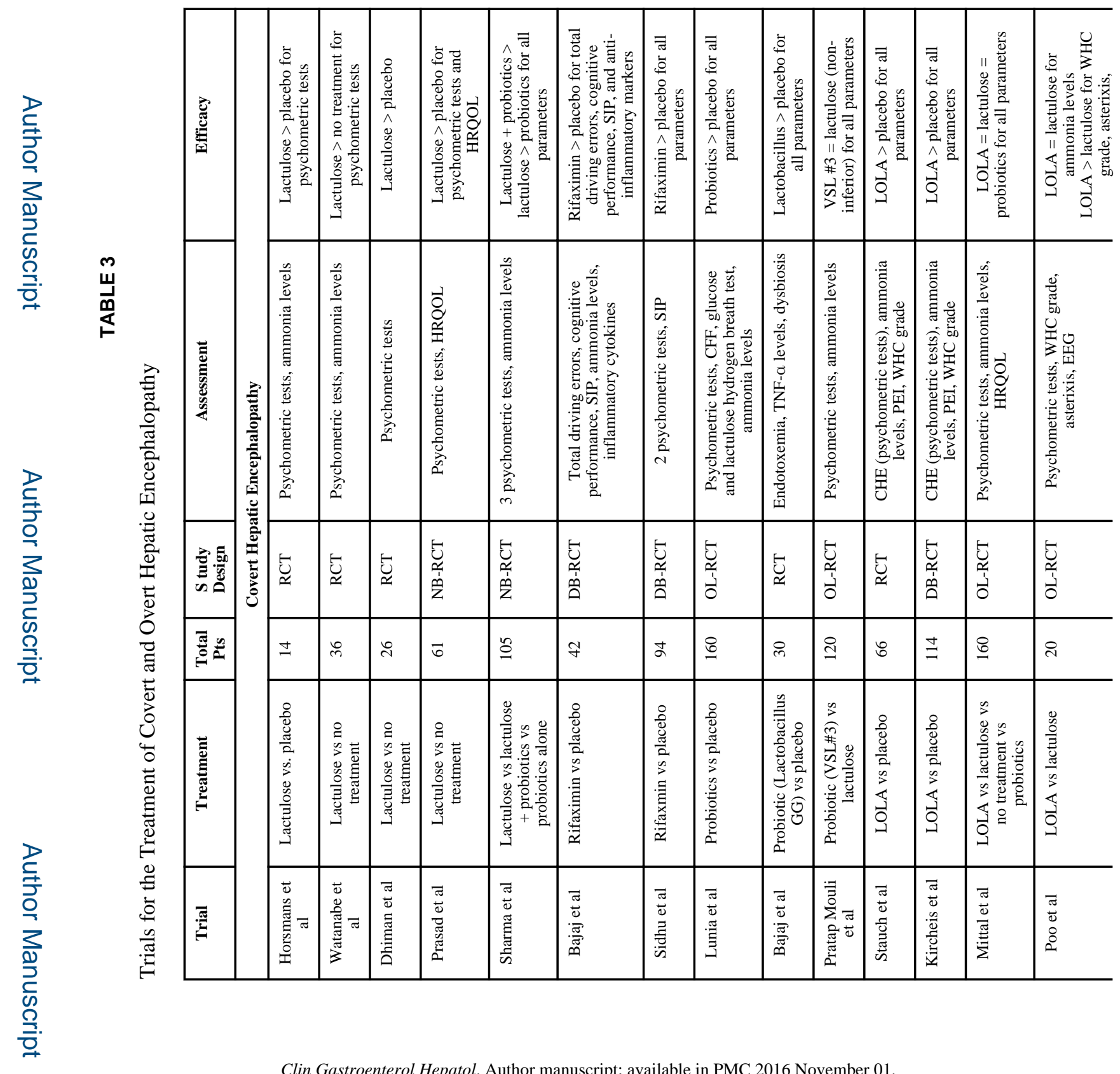




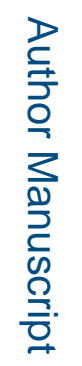

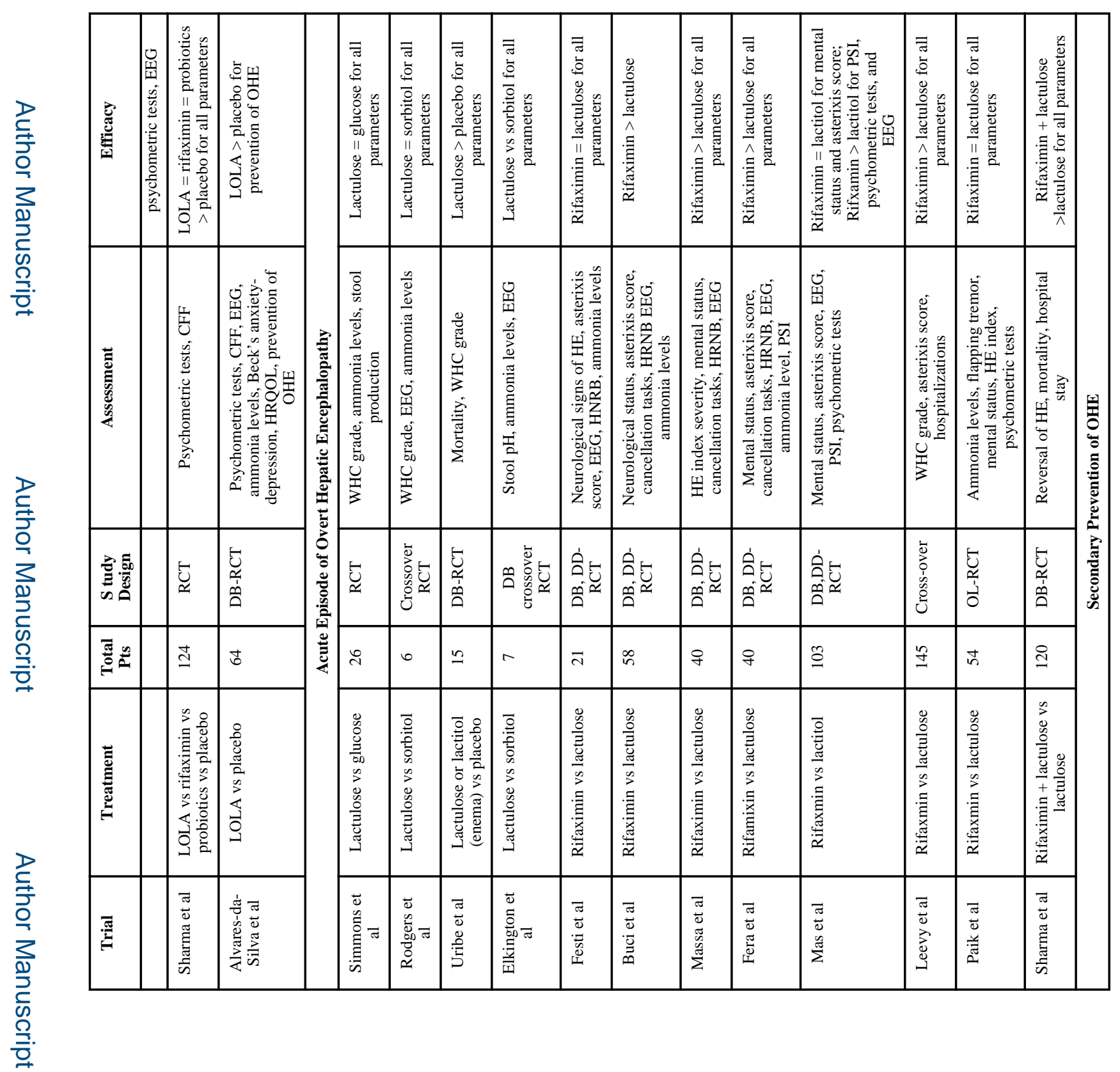

Clin Gastroenterol Hepatol. Author manuscript; available in PMC 2016 November 01. 


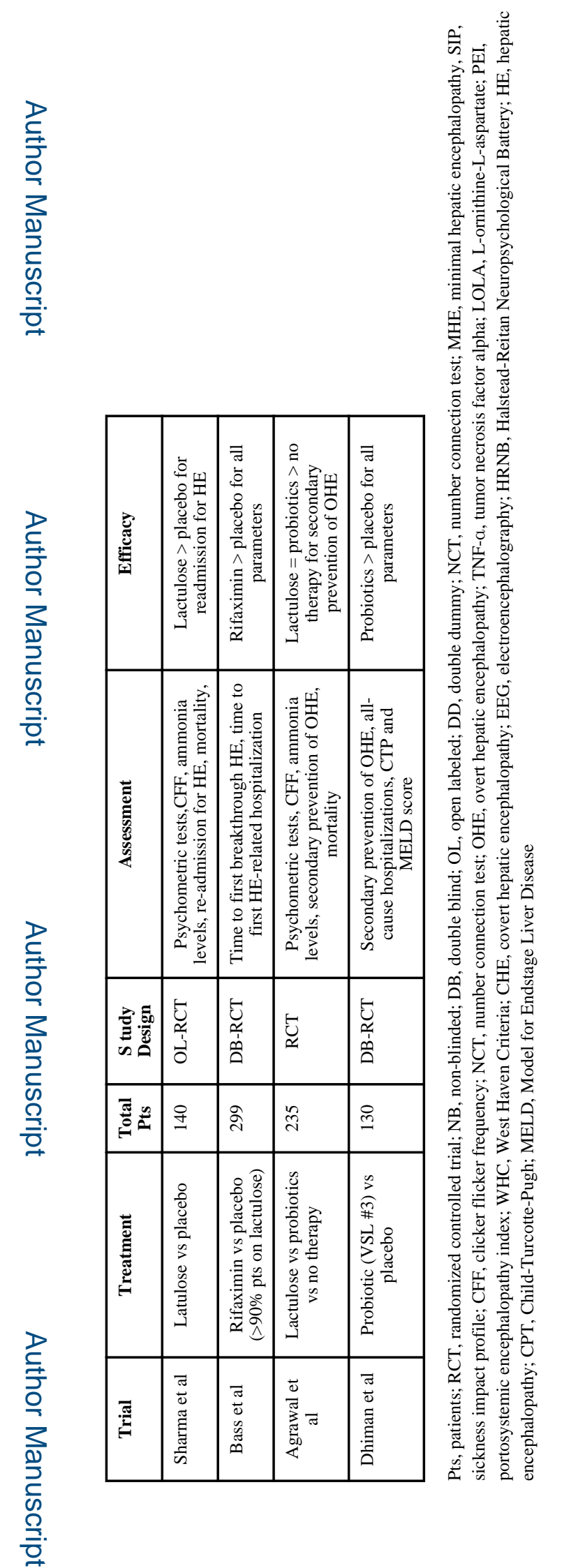

Clin Gastroenterol Hepatol. Author manuscript; available in PMC 2016 November 01. 